\title{
Adaptive Fuzzy Model for Determining Quality Assessment Services in the Supply Chain
}

\author{
Milovan TOMAŠEVIĆ, Nebojša RALEVIĆ, Željko STEVIĆ, Vidan MARKOVIĆ, Zdravko TEŠIĆ
}

\begin{abstract}
The problem that is being addressed in this paper is to improve the services provided by company and achieve better communication between companies in the supply chain. Therefore, a qualitative assessment of service has been required. This service is characterized by a group of parameters, which are often inaccurately estimated values, as well as their importance for the evaluation system. This is often the result of assessor's uncertainty, variability of conditions, etc. Therefore, in the context of AM4SCM (Adaptive Model for Supply Chain Management) a mathematical model for evaluating the quality of services has been developed (FAM4QS - Fuzzy Aggregation Method for Quality Service) which is based on the fuzzy arithmetic. Selection of different values for the degrees of fuzzy power mean, which are used for evaluation of parameters or groups of parameters of the system and the service, contributes to a better assessment and it is due to the varying nature of the parameters. The observed model was simulated on 17 supply chains on the territory of the Republic of Serbia. Service quality assessment is carried out based on data from the user requirements participants of supply chains binding the so-called fuzzy aggregation function.
\end{abstract}

Keywords: AM4SCM (Adaptive Model for Supply Chain Management); Software quality; Software services; Supply Chain Management

\section{INTRODUCTION}

The concept of supply chain changes over time. It is gaining in importance. During the first decade of this century, according to [1], supply chain management and control were the strategic focus of the leading manufacturing companies. This is caused by rapid changes of environment in which companies operate, the globalization of markets and very high customers' requirements where high quality products and services are becoming a priority. The aim of for today's supply chain is to model the supply chain in a way that will provide profitable outputs for all parts of the supply chain and its participants. Looking at one of the supply chain definitions, according to [2], it is a set of three or more organizations that are directly connected with one or more flows of products, services, finance and information flows from a source to the end user in contemporary supply chains, and very often it is necessary to coordinate activities and flows to the extent that goes beyond the current limits. Supply chain management has a high impact on the quality of products and services, which according to [3] increases the importance of the relationship between procurement, suppliers and quality. With the increasing importance of these relationships, the aim is to optimize the supply chain which, according to [4], aims to successfully control the different elements within the chain, which include the participants, their mutual contacts and relationships, and the way of organizing certain internal activities.

In addition to cost optimization, the aim of supply chain management is to improve the flow of information between the suppliers, companies and distributors. As one of the important aims of supply chain management, which has lately been emphasized, is to increase the quality of service and flexibility in order to achieve the satisfaction of the end users. This is confirmed by Christopher in his book [5], "the whole purpose of supply chain management and logistics is to provide customers with level and quality of service that they required and to do so less cost to the total supply chain".

When it comes to supply chain the flow of information in a real time is one of the global problems. Many researches are focused on solving this problem and ensuring the flow of information in real time in the supply chain, so that participants are more satisfied and do business better. Problems often arise due to poor connectivity of subsystems that are independently developed and used as global integrators of all company processes. Within the subsystem, solutions for individual functions are given only as a set of fixed partial solutions without generalization. It is often possible to find a system whose structure is not specially projected; however, the solution is sought in the merger (purchase) of subsystems where the partial solutions occurred during the time of need. The subjects of this study are model, method and tools for supply chain management used to the greatest extent possible using the concepts of responsibility for the flow of information, increasing the quality of service in real time in the supply chain.

According to Cheng [6] due to its complexity and uncertainty, quality control of supply chain represents great challenges to practitioners and researchers, so the problem considered in this article is to improve the service provided by the company and to achieve better communication between the companies in the supply chain, in order to accelerate their business and deliver more profit, as well as to exert greater cooperation with customers and to continue good business relation with them.

In addition, the investigated problem is the service qualitative assessment, when it is characterized by a group of parameters which are often inaccurately estimated values, as well as its importance for the evaluation system. This imprecision is often the result of assessor's uncertainty, variability of conditions, etc. Since imprecise data will be employed, the goal of this study is to introduce acceptable methodology or assessors (functions) for evaluating the quality of service. The assessor should be able to deal with imprecise data.

This paper is structured as follows. In section 2 is shown literature review and the need for research. Section 3 presents description of the model, while section 4 presents verification and simulation of the model with discussion. Section 5 derives conclusions and directions for future research. 


\section{LITERATURE REVIEW}

This is the time when companies cannot rely on their own inventive and productive abilities [7]. So, nowadays the center of gravity is not a competition among the organizations - it has been shifted toward the supply chain $[8,9]$.

In addition to facing global competition, companies are faced with customers who change their requirements very quickly, but are also dealing with the technological changes that influence reduction of critical reactions when it comes to competence [10-12].

Therefore, firstly special attention should be paid to the supply chain at the first place, supply partners, improvement and acceleration of products and services [7]. These competencies are of particular importance for the firms with identified market changes. Therefore, they should turn towards integrated supply chain in order to positively and effectively respond to these changes [13, 14]. Adequate management of the modern supply chain requires quality inputs, further reflected on its full flow. To provide that the purpose of the supply chain is satisfying user needs and requirements, the essential aim of the modern supply chain is the integration of all possible activities and processes that need to bring greater value to the end user. Supply chain integration (SCI) has positive impact on performances of companies [15-17] and helps firms to reconfigure their resources and capabilities internally and externally [18]. Supply chain integration may be more crucial in early stages and when that process is completed, a company can focus on SCM practice and competition capability [19]. Also supplier integration has a strong and positive impact on schedule attainment and customer satisfaction [20].

According to Nagurney [21] quality is one of the most essential factors for the success of supply chains, but also quality of service according to [22] is still one of the major problems with consumers. Consequently, due to ensuring the continuous improvement of quality service that leads to customer satisfaction, the study investigated the effect of external knowledge and knowledge chain to quality of service. Companies should use the chain of knowledge to collect the external knowledge from the customers, suppliers and competitors, as well as transformation of knowledge to improve their quality of service.

The need for research and improvement of the system for solving user's problem arises from the current situation which companies are faced with, due to continual increase of users who need IT (information technology) services. According to [23] one of two approaches for improvement of business performance is integrated information technology. Pieces of information and their quality have a high impact on the whole supply chain, because poor information quality according to [24] may lead to organizational losses such as losing customers, missing opportunities, and making incorrect decisions. The significant role and impact of information sharing in supply chains have been extensively studied [25-28]. Apart from better information sharing, the connectivity among partner firms that enables information integration is crucial for firms to realize customer service performance gains [29].

The main objective of the research is the development of models that can respond to as many user requests as possible. It is a system that will serve companies to converge towards continuous quality improvement in the delivery of their IT services. The system that has emerged from this study, with the given specification, is a part of the model, which is subjected to changes and upgrades, which means that it will eventually improve over time. In order to stay competitive, it is important to constantly improve the quality of services and software as well as to respond to the latest needs faster than it is now being done, i.e. to be more agile.

\section{THE MODEL AND METHOD}

To assess the parameters of service it is advisable to take an arithmetic mean of the phenomenon with a normal distribution, but if it is not the case, then it is often better to take a different assessment as aggregation functions specially degree environments [30, 31]. Diversity of choice values of degrees of that environment implies more or less disjunctively or conjunctively of forms selected aggregation functions (higher $r$ disjunctive form, less $r$ conjunctive form). In the paper [32], quality of services was improved by using the aggregation functions in the LSP method.

Taking the mid-stage of the aggregation instead of the typical one, due to the inaccuracy of data which are handled and which look like some of the triangular fuzzy numbers, the same as when evaluating the overall system, the fuzzy number, i.e. the interval of values with different values of the membership function, is received. Defuzzification provides better value in comparison with conventional method. To avoid harsh conclusion i.e. the answer for the quality assessment system is a number, in that case the response was an interval of values that is actually alpha-section of the stage as the number of output where alpha belongs to the desired degree of aggregation functions [33].

In this chapter, SSSI (the six-step service improvement method used lsp) method has been presented. Its main feature is that the power mean has been used for quality of service with weight coefficients in which the degree changes, if necessary, depending on whether more or less characteristics of conjunctive or disjunctive form are required. The parameters that appear in this formula which are characteristics of the system as well as the weight coefficients are a matter of judgment of the team of experts. The results are presented.

Algorithm of the SSSI method for assessing the quality of the software consists of the following steps [32]:

1. Select a group from the category of services (same rank) in the catalog of services;

2. Use the lsp method. The formula for calculating the estimates for each of these criteria is given by [34]:

$E=\left(\sum_{i=1}^{k} w_{i} e_{i}^{r}\right)^{\frac{1}{r}}, 0 \leq w_{i} \leq 1, \sum_{i=1}^{k} w_{i}=1, e_{i} \in[0,1], E \in[0,1], k \geq 2(1)$

where $w_{i}$ the coefficients weight, $r$ value based on the expectation of the combined impact of taking into account the priority level of the group. $r$ takes values from $-\infty$ (full conjunction) to $+\infty$ (full disjunction);

3. Identification of the criteria comparisons;

4. Computation preference (priority) for each service selected rank; 
5. Analysis of the results and selection of the best ranked in the group- UCL (upper control limit) and LCL (lower control limit) [35];

6. If it is possible perform understandable conclusion and recommendation to improve service on the basis of knowledge gained in the previous step, and if not we will continue with another tour cycle.

Adaptive model for supply chain management is a complex system that connects the functional and interfunctional business processes and allows participants in the supply chain management of processes in real time (see Fig. 1). It consists of:

- $\quad$ Model for supply chain management (BSCMS)

- Model for managing user requirements (Service Desk)

- Model for assessing the quality of services provided (FAM4QS).

The hierarchical structure of the adaptive model for supply chain management (AM4SCM) is shown in Fig.1 with seven levels of activity and feedback interfaces that enable continuous improvement of AM4SCM.

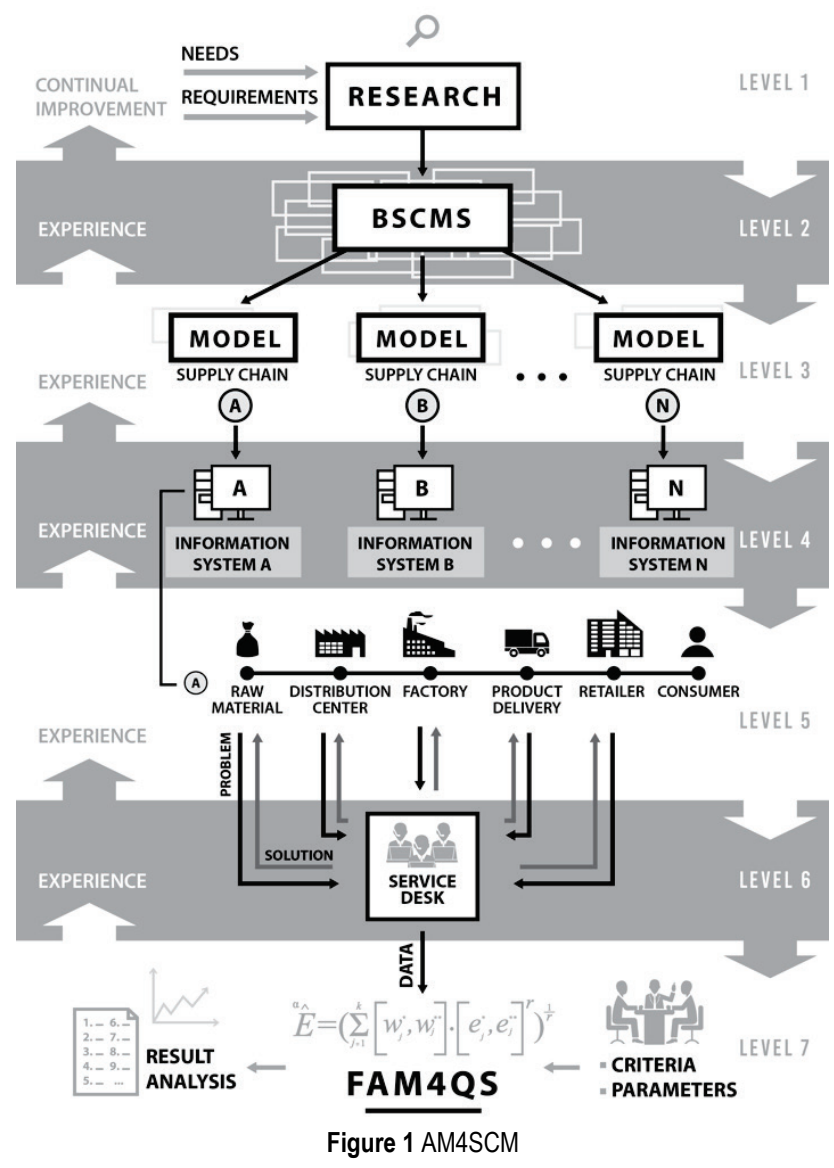

LEVEL 1 requires that the conducted system analysis enables, defines and coordinates the following activities:

- Determination of the current state of IT systems used (if applicable)

- Defining the town of generating information and control procedures and data entry,

- Definition of potential users,

- Requirements for potential beneficiaries,

- Determining the level of access to projected information,

- Define and generate the necessary level of information,
- Harmonization of information with other participants participating in the chain

- Post analysis system to the project team to create software,

- Control of the draft software,

- Set up links to all relevant actors,

- Evaluation of the project and definition of any changes in the concept and flow of information based on the real needs of relevant stakeholders called in the supply chain.

LEVEL 2 A general model for supply chain management makes use of the case with its activities covering the vast majority of premium features for business and they are presented in the following diagram. At LEVEL 3 the model has been adjusted to company requirements by choosing from the previous processes if they exist or otherwise they are created. LEVEL 4 or process consists of four steps. The first step includes defining the partners, defining data and documents needed for the operation after which the rules on the exchange of information and their availability are set out. At LEVEL 5, the selected processes are implemented and adapted by the company. LEVEL 6 is connecting with the Service Desk system which is shown in Fig. 2.

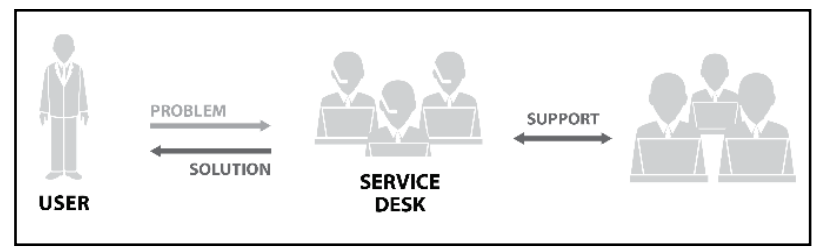

Figure 2 Service desk

LEVEL 7 represents FAM4QS method that differs from the previous one [34] in the way that the parameter estimation and weight coefficients of the team of experts are presented as fuzzy triangular numbers due to their imprecision. As a result there is a review of the system in the form of fuzzy numbers, respectively the interval as its $\alpha$-cut. If desired, the response can be defuzzyficated by the method of gravity. Due to better understanding of the method that deals with imprecise data, some of the concepts from the theory of fuzzy sets and properties associated with them should be considered.

The theory of fuzzy sets generalizes traditional theory, so that instead of the characteristic function (which takes a value of 1 for the given element $x$ if $x \in A$, and a value of 0 if $x \notin A$ ) we observe the so-called membership function $\mu_{A}$ of this set, which determines the grade of membership of the element $x$ to the set $\mathrm{A}$ that is no longer just 0 and 1 but it can take any value from the interval $[0,1]$, i.e. $\mu_{A}(x)$ $\in[0,1]$.

In this study special fuzzy sets will be used - fuzzy numbers and the so-called triangular fuzzy numbers: $A=$ $(l, m, r)$ where $l$ is called the left boundary of triangular fuzzy number, $m$ is the value which belongs to the core of fuzzy number (membership function is 1), and $r$ is the right boundary of the triangular fuzzy number. Depending on the nature of the data, i.e. our estimate (whether accurate or not) shall modify the aforementioned formula (see (1)) for certain imprecise $e_{i}$ or inaccurately estimated weights $w_{i}$ as follows. 
$\hat{E}=\left(\hat{w}_{1} \cdot \hat{e}_{1}^{r}+\ldots+\hat{w}_{n} \cdot \hat{e}_{n}^{r}\right)^{\frac{1}{r}}$

Fuzzy numbers that represent the weight and evaluation of individual parameters were marked with $\hat{w}_{i}$ and $\hat{e}_{i}, i=1, \ldots, n$.

It is given that an interval-valued estimate for each individual service (as $\alpha$-cut) is as follows: $\left[E_{i}^{*}, E_{j}^{*}\right], i=$ $1, \ldots, n$. After receiving the results of interval values in methods FAM4QS ranking service from the lowest $C$, medium $\mathrm{B}$ and the highest $\mathrm{A}$ will be done according to the following criteria:

The mean value of the intervals $\left[E_{i}^{*}, E_{j}^{*}\right], i=1, \ldots, n$ :

$E=\left[\frac{1}{n} \sum_{i=1}^{n} E_{i}^{*}, \frac{1}{n} \sum_{i=1}^{n} E_{i}^{* *}\right]$

Interval value obtained by previous adding, for example $\pm 5 \%$ (or $\pm 10 \%$ ), on the left and right boundary of interval

$$
\begin{aligned}
U C L & =\left[1.05 \cdot \frac{1}{n} \sum_{i=1}^{n} E_{i}^{*}, 1.05 \frac{1}{n} \sum_{i=1}^{n} E_{i}^{* *}\right], \\
I C L & =\left[0.95 \cdot \frac{1}{n} \sum_{i=1}^{n} E_{i}^{*}, 0.95 \frac{1}{n} \sum_{i=1}^{n} E_{i}^{* *}\right],
\end{aligned}
$$

provides a selection criterion whether a service belongs to the highest (A) or the lowest rank (C). Those services that have a core (peak) or $\alpha$-cut for $\alpha=1$ greater than the right border $U C L$ have the highest rank, and the services whose core is less than the left border $L C L$ have the lowest rank. Firms whose core is within left boundary of $L C L$ and $U C L$ right boundary are mid-level services (B).

Diagram of activities for FAM4QS is shown in Fig. 3.

Note: The number $r$ is also a real number different from zero and does not have to be the same as values $r$ (from the formula for assessment $e_{j}$ that is analog to formula (2)). By changing the value of $r$ (respectively $r_{j}$ ) it has obtained the characteristics of the disjunctive or conjunctive forms for evaluation services (parameters). By increasing $r(r \rightarrow+\infty)$ disjunctively grows and conjunctively decreases, by reducing $r(r \rightarrow-\infty)$, disjunctively declines, and conjunctively grows. Due to assessment of relevant parameters, the assessment of $r_{j}$ and $r$ depends on whether it is to be more disjunctive or conjunctive. Characteristic of conjunctive form is that a bad score of at least one parameter gives a bad score of the whole service, and only good reviews of all parameters provide a good assessment of an entire service; while for the disjunctive form a bad score for the entire service results when all the parameters are evaluated as poor. The service is rated good if at least one parameter is evaluated as good. The values for $r$ can be found in [36].

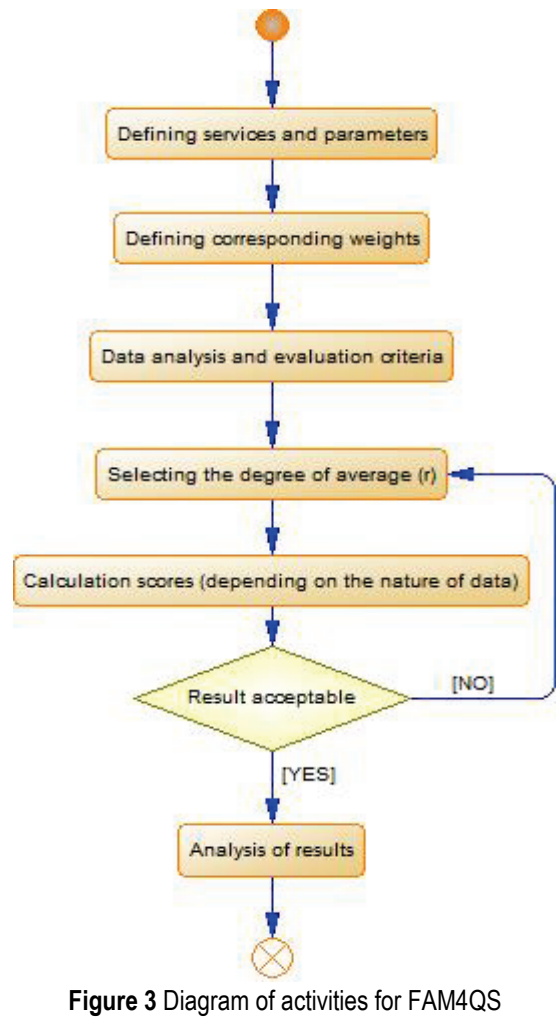

4 VERIFICATION AND SIMULATION OF THE MODEL

Application of a system of 17 supply chains in Serbia by fuzzy method has been made in the head of FAM4QS application. The first step of FAM4QS implementation is to organize services of the same group. Below services are grouped according to certain criteria set by the definition. The service grouping as a first step of identification was done based on the identified service class group attributes [32]:

1. Technology group is represented by technical attributes that better describe influence of applied technology tools on service development and operations.

2. Complexity group represented observed level of complexity in creating solution. More tiers in the solution implementation in most cases represent more complexity in service operation.

3. Development process group represented the possibility to lever the influence on the service by applied development process. Some development processes created very stable service, but had a problem with low level of flexibility towards change.

4. Development of team group - team experiences, skills, team cohesion, in house and outsourcing options that affect the ability for quality maintenance of specific service.

5. Business support domain group relates to the end user profile, number, location, and a type of application that is being used (for example, OLTP, reports, etc.).

6. In this case study we identified the following value domains for the above group attributes:

a. For technology dependent group attribute $T D_{i}$, the study identifies two-tier, three-tier and four-tier client server architecture, Web platform on Open Source, Web platform on proprietary (Oracle) platform, and 
programming languages: Java, VB6, $\mathrm{C}++$, and Oracle PL/SQL.

b. Complexity group attribute $C_{i}$, takes high, medium and low values.

7. Different services were developed using different development process $D P_{i}$. These processes in this case were: Procedural SSA (Structured Systems Analysis),

8. RUP, Agile (Scrum), Hybrid.

9. Development of team group $T D_{i}$ was different for different services. The services were developed and maintained internally $(\mathrm{IH})$, externally $(\mathrm{OH})$, and mixed teams (MX).

10. Business support domain group $B D_{i}$ was described by values (Yes/No) for the following attributes front-end support, back-end support, internal user's domain, external user's domain, OLTP, reporting facilities.

Based on these group attributes definition, each instance of service class $S_{i}$ from the catalog was assigned the values as the following:

$S_{i}=\left(T D_{i}, C_{i}, D P_{i}, D T_{i}, B D_{i}\right)$,

where:

$T D_{i}=\left(t d_{1}, t d_{2}, t d_{3}\right)$ where $t d_{1} \in\{2 T, 3 T, 4 T\}$, $t d_{2} \in\{W O, W P, D C\}, t d_{3} \in\{J, V B, C ; D\}, C_{i}=(c)$, where $c \in\{H I, M I, L O\}, D P_{i}=(d p)$, where $d p \in\{S, R, A, H\}, D T_{i}=(d t)$, where $d t \in\{I N, O H, M X\}$, $B D_{i}=\left(b d_{1}, b d_{2}, b d_{3}\right)$, where $b d_{1} \in\{F E, B E\}$, $b d_{2} \in\{O L, R E\}, b d_{3} \in\{I N, E X\}$

Value domains are:

TD : $2 T-$ Two $\cdots$ Tier, $3 T$ - Three $\cdots$ Tier, $4 T-$ Four $\cdots$ Tier ,

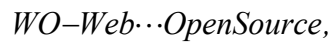

WP-Web $\cdots$ Proprietary, DC-DesktopClient( FatClient),

J-Java, VB-VisualBasic, $C-C++, D-D o t N e t$;

$C$ : HI-High,MI-Medium, LO-Low;

$D P: S-S S A, R-R U P, A-$ Agillity, $H-H y b r i d ;$

$D T: I H-I n \cdots$ House, OH - Out $\cdots$ House, $M X$ - Mixed;

$B D: F E-F r o n t E n d, B E-B a c k E n d, O L-O L T P, R E-R e$ ports, IN - InternalUser, eX-ExternalUser

$w_{1}=(0.45 ; 0.5 ; 0.6) ; \quad w_{2}=(0.05 ; 0.15 ; 0.2) ; \quad w_{3}=(0.20 ; 0.35 ; 0.45)$,

$w_{11}=(0.25 ; 0.3 ; 0.4) ; w_{12}=(0.65 ; 0.7 ; 0.8)$,

$w_{21}=(0.4 ; 0.5 ; 0.55) ; w_{22}=(0.45 ; 0.5 ; 0.6)$,

$w_{31}=(0.25 ; 0.3 ; 0.4) ; \quad w_{32}=(0.45 ; 0.5 ; 0.6) ; \quad w_{33}=(0.15 ; 0.2 ; 0.35)$.

The parameters to be used to complete evaluation of services are shown in Tab. 1. Tab. 2 shows the grouping of the same rank.

Due to better coordination quality of service observed it is suggested to define measurement period that is as long as possible (one year) with all the data collected during this time.
Table 1 Parameters for evaluation

\begin{tabular}{|c|c|}
\hline Groups & Subgroups \\
\hline \multirow{2}{*}{$\mathrm{P}_{1}=\mathrm{QS}$ (Quality of service) } & $\mathrm{P}_{11}=$ Number of incidents \\
\hline & $P_{12}=$ The average time of solving \\
\hline \multirow{2}{*}{$\mathrm{P}_{2}=$ Documentation } & $\begin{array}{l}\mathrm{P}_{21}=\text { The documentation inside } \\
\text { the code }\end{array}$ \\
\hline & $\begin{array}{l}\mathrm{P}_{22}=\text { The documentation outside } \\
\text { the code }\end{array}$ \\
\hline \multirow{3}{*}{$\mathrm{P}_{3}=$ Responsibility of the customer } & $\mathrm{P}_{31}=$ Flexibility \\
\hline & $\mathrm{P}_{32}=$ Expense \\
\hline & $P_{33}=$ Stability \\
\hline
\end{tabular}

Table 2 Clustering service

\begin{tabular}{|c|c|c|c|c|c|}
\hline \\
\hline Product ID & TD & $\mathrm{C}(\mathrm{H} / \mathrm{M} / \mathrm{L})$ & $\mathrm{DP}$ & DT & $\mathrm{BD}$ \\
\hline SCM 1 & $3 \mathrm{~T}, \mathrm{WO}, \mathrm{J}$ & $\mathrm{H}$ & $\mathrm{A}$ & $\mathrm{OH}$ & FE, OL, IN \\
\hline SCM 2 & $3 \mathrm{~T}, \mathrm{WO}, \mathrm{J}$ & $\mathrm{H}$ & $\mathrm{A}$ & IN & FE, OL, IN \\
\hline SCM 3 & $3 \mathrm{~T}, \mathrm{WO}, \mathrm{J}$ & $\mathrm{H}$ & $\mathrm{A}$ & IN & FE, OL, IN \\
\hline SCM 4 & $3 \mathrm{~T}, \mathrm{WO}, \mathrm{J}$ & $\mathrm{H}$ & $\mathrm{A}$ & $\mathrm{OH}$ & FE, OL, IN \\
\hline SCM 5 & $3 \mathrm{~T}, \mathrm{WO}, \mathrm{J}$ & $\mathrm{H}$ & $\mathrm{A}$ & IN & FE, OL, IN \\
\hline SCM 6 & $3 \mathrm{~T}, \mathrm{WO}, \mathrm{J}$ & $\mathrm{H}$ & A & $\mathrm{OH}$ & FE, OL, IN \\
\hline SCM 7 & $3 \mathrm{~T}, \mathrm{WO}, \mathrm{J}$ & $\mathrm{H}$ & $\mathrm{A}$ & IN & FE, OL, IN \\
\hline SCM 8 & $3 \mathrm{~T}, \mathrm{WO}, \mathrm{J}$ & $\mathrm{H}$ & $\mathrm{A}$ & $\mathrm{OH}$ & FE, OL, IN \\
\hline SCM 9 & $3 \mathrm{~T}, \mathrm{WO}, \mathrm{J}$ & $\mathrm{H}$ & $\mathrm{A}$ & $\mathrm{OH}$ & FE, OL, IN \\
\hline SCM 10 & $3 \mathrm{~T}, \mathrm{WO}, \mathrm{J}$ & $\mathrm{H}$ & $\mathrm{A}$ & IN & FE, OL, IN \\
\hline SCM 11 & $3 \mathrm{~T}, \mathrm{WO}, \mathrm{J}$ & $\mathrm{H}$ & $\mathrm{A}$ & IN & FE, OL, IN \\
\hline SCM 12 & $3 \mathrm{~T}, \mathrm{WO}, \mathrm{J}$ & $\mathrm{H}$ & A & IN & FE, OL, IN \\
\hline SCM 13 & $3 \mathrm{~T}, \mathrm{WO}, \mathrm{J}$ & $\mathrm{H}$ & $\mathrm{A}$ & IN & FE, OL, IN \\
\hline SCM 14 & $3 \mathrm{~T}, \mathrm{WO}, \mathrm{J}$ & $\mathrm{H}$ & $\mathrm{A}$ & IN & FE, OL, IN \\
\hline SCM 15 & $3 \mathrm{~T}, \mathrm{WO}, \mathrm{J}$ & $\mathrm{H}$ & $\mathrm{A}$ & $\mathrm{OH}$ & FE, OL, IN \\
\hline SCM 16 & $3 \mathrm{~T}, \mathrm{WO}, \mathrm{J}$ & $\mathrm{H}$ & $\mathrm{A}$ & $\mathrm{OH}$ & FE, OL, IN \\
\hline SCM 17 & $3 \mathrm{~T}, \mathrm{WO}, \mathrm{J}$ & $\mathrm{H}$ & $\mathrm{A}$ & IN & FE, OL, IN \\
\hline
\end{tabular}

Table 3 Number of user requirements by service

\begin{tabular}{|c|c|c|c|c|c|c|c|c|c|c|c|c|c|c|c|c|c|}
\hline $\begin{array}{c}\text { Month/ } \\
\text { SCM }\end{array}$ & 1 & 2 & 3 & 4 & 5 & 6 & 7 & & 9 & 10 & 11 & 12 & 13 & 4 & 15 & 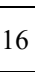 & 17 \\
\hline 1 & 60 & 2 & 33 & 0 & 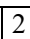 & 2 & 0 & 0 & 1 & 0 & S & 1 & S & & 7 & & 1 \\
\hline 2 & 12 & 3 & 35 & 2 & 0 & 6 & 0 & & 3 & 0 & & 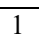 & 0 & & 7 & 2 & 1 \\
\hline 3 & 29 & 8 & 60 & 1 & 0 & 7 & 0 & ( & 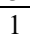 & 0 & 5 & 4 & 2 & 1 & 6 & 0 & 1 \\
\hline 4 & 13 & 4 & 43 & 1 & 0 & 9 & 0 & 2 & 5 & 1 & 1 & 4 & 0 & 2 & 16 & 0 & 0 \\
\hline 5 & 15 & - & 22 & 1 & 0 & 1 & 0 & & 0 & 1 & 1 & 2 & 0 & 2 & 1 & 0 & 1 \\
\hline 6 & 21 & 3 & 53 & 2 & 0 & 5 & 0 & 1 & 2 & 0 & 2 & 2 & 0 & 4 & 11 & 2 & 2 \\
\hline I & 11 & 4 & 38 & 2 & 0 & 3 & 0 & ( & 1 & 0 & 1 & 0 & 0 & 1 & 4 & 0 & 0 \\
\hline 8 & 13 & 2 & 25 & 2 & | & 4 & 0 & $J$ & 6 & 2 & 2 & 2 & 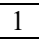 & & 4 & 2 & 0 \\
\hline 9 & 22 & 9 & 33 & 2 & 1 & 2 & 0 & 1 & 8 & 2 & 2 & 0 & 0 & 3 & 10 & 1 & 1 \\
\hline 10 & 16 & 4 & 29 & 2 & 0 & 6 & 0 & 4 & 9 & 0 & 2 & 3 & 0 & 2 & 9 & 1 & 2 \\
\hline 11 & 9 & 9 & 21 & 2 & 1 & 4 & 0 & & 6 & 0 & 4 & 0 & 0 & 3 & 1 & 0 & 0 \\
\hline 12 & 16 & 4 & 9 & 2 & 1 & 5 & 1 & & 2 & 0 & 3 & 2 & 1 & 6 & 4 & 0 & \\
\hline
\end{tabular}

Table 4 Estimates for the number of service user requirements

\begin{tabular}{|c|c|c|c|c|}
\hline Rank & Score & SCM & User req. & Scored \\
\hline $0-25$ & 0.9 & 1 & 237 & 0.1 \\
\hline $26-40$ & 0.8 & 2 & 55 & 0.7 \\
\hline $41-60$ & 0.7 & 3 & 401 & 0.1 \\
\hline $61-75$ & 0.6 & 4 & 19 & 0.9 \\
\hline $76-90$ & 0.5 & 5 & 6 & 0.9 \\
\hline $91-120$ & 0.4 & 6 & 54 & 0.6 \\
\hline $121-150$ & 0.3 & 7 & 1 & 0.9 \\
\hline $151-190$ & 0.2 & 8 & 13 & 0.9 \\
\hline $191+$ & 0.1 & 9 & 5 & 0.9 \\
\hline & & 10 & 6 & 0.9 \\
\cline { 3 - 5 } & & 11 & 2 & 0.9 \\
\cline { 2 - 5 } & 12 & 21 & 0.9 \\
\cline { 2 - 5 } & 13 & 4 & 0.9 \\
\cline { 2 - 5 } & & 14 & 34 & 0.8 \\
\cline { 3 - 5 } & 15 & 80 & 0.5 \\
\cline { 3 - 5 } & & 16 & 9 & 0.9 \\
\cline { 3 - 5 } & 17 & 10 & 0.9 \\
\hline
\end{tabular}

Estimates were presented with the following criteria for services according to the user requirements that are shown with crisp values.

Estimates for the average time of solving the problem is rendered according to the following criteria - see Tab. 5 . 
Table 5 Estimates of services for the average time of solving customer requests

\begin{tabular}{|c|c|c|c|c|}
\hline Rank & Score & SCM & Time & Scored \\
\hline $0-3$ & 0.9 & 1 & 7.19 & 0.7 \\
\hline $3-6$ & 0.8 & 2 & 13.32 & 0.4 \\
\hline $6-9$ & $0, .7$ & 3 & 3.40 & 0.9 \\
\hline $9-11$ & 0.6 & 4 & 25.46 & 0.1 \\
\hline $11-13$ & 0.5 & 5 & 2.86 & 0.9 \\
\hline $13-15$ & 0.4 & 6 & 4.14 & 0.8 \\
\hline $15-17$ & 0.3 & 7 & 18.13 & 0.2 \\
\hline $17-20$ & 0.2 & 8 & 32.30 & 0.1 \\
\hline $20+$ & 0.1 & 9 & 6.58 & 0.7 \\
\hline & & 10 & 6.30 & 0.7 \\
\cline { 2 - 5 } & & 11 & 14.92 & 0.4 \\
\cline { 2 - 5 } & & 12 & 8.80 & 0.7 \\
\cline { 2 - 5 } & 13 & 11.31 & 0.5 \\
\cline { 2 - 5 } & & 14 & 11.07 & 0.5 \\
\cline { 3 - 5 } & & 15 & 6.49 & 0.7 \\
\cline { 3 - 5 } & & 16 & 9.04 & 0.6 \\
\cline { 3 - 5 } & & 17 & 5.77 & 0.8 \\
\hline
\end{tabular}

The average time $(\mathrm{h})$ of resolving customer requests for services (17) over a period of 12 months Tab. 6 .

\section{Service results movement by interval}

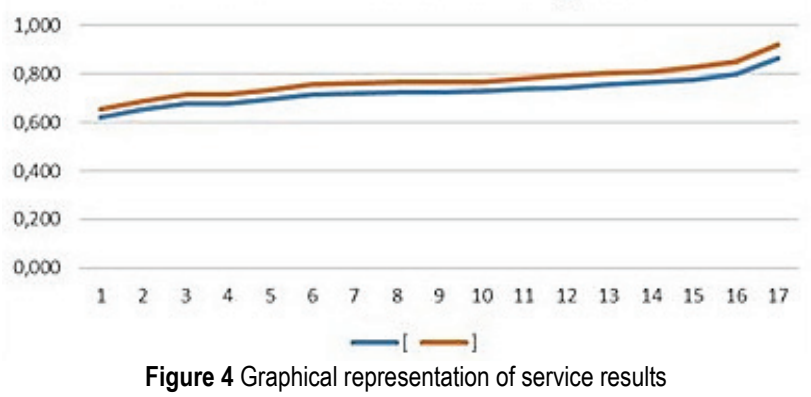

In Fig. 5 it is shown that the best service (5) does not have any problems in the period from the second to the eighth month, even in the tenth month it was functioning smoothly. Regarding service 14 , which is the worst, it can be seen that it has higher oscillations in the beginning compared to the later period. In Fig. 6, it can be observed that the service 5 almost has no serious problems in its functioning until the end of the year.

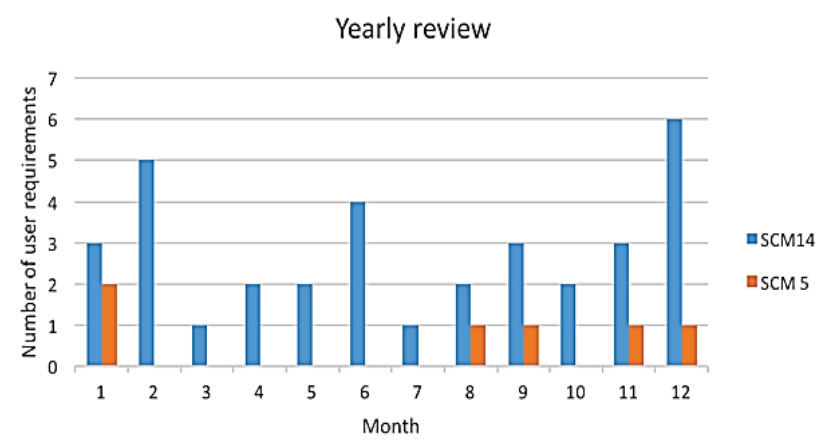

Figure 5 Comparative analysis of the best and the worst rated service by number of received users requests by months.

Yearly review

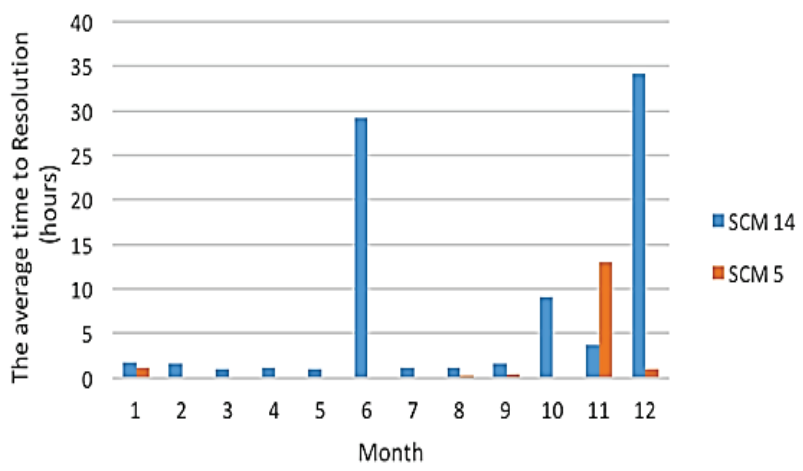

Figure 6 Comparative analysis of the best and the worst rated services according to an average time for solving users requirements

\begin{tabular}{|c|c|c|c|c|c|c|c|c|}
\hline Month/SCM & 1 & 2 & 3 & 4 & 5 & 6 & 7 & 8 \\
\hline 1 & 1.82 & 0.56 & 2.68 & 0 & 1.19 & 0.11 & 0 & 0 \\
\hline 2 & 2.94 & 2.07 & 5.12 & 31.57 & 0 & 0.44 & 0 & 0 \\
\hline 3 & 9.48 & 4.23 & 3.28 & 25.10 & 0 & 1.94 & 0 & 0 \\
\hline 4 & 16.67 & 2.54 & 5.36 & 26.04 & 0 & 9.21 & 0 & 3.48 \\
\hline 5 & 4.17 & 1.12 & 2.28 & 36.02 & 0 & 10.52 & 0 & 0 \\
\hline 6 & 11.19 & 9.73 & 2.01 & 58.30 & 00 & 5.83 & 0 & 0.10 \\
\hline 7 & 4.30 & 144.33 & 1.52 & 15.10 & 0 & 14.32 & 0 & 0 \\
\hline 8 & 14.91 & 0.74 & 4.20 & 23.83 & 0.28 & 0.80 & 0 & 45.22 \\
\hline 9 & 6.01 & 1.13 & 4.69 & 12.01 & 0.44 & 0.63 & 0 & 1.02 \\
\hline 10 & 12.65 & 6.46 & 4.30 & 24.36 & 0 & 3.60 & 0 & 68.78 \\
\hline 11 & 5.73 & 3.35 & 2.83 & 15.06 & 13.05 & 3.45 & 0 & 0 \\
\hline 12 & 8.88 & 0.89 & 1.23 & 18.04 & 1.04 & 0.38 & 18.13 & 0.55 \\
\hline 9 & 10 & 11 & 12 & 13 & 14 & 15 & 16 & 17 \\
\hline 1.09 & 0 & 0 & 3.11 & 0 & 1.72 & 1.20 & 1.23 & 0.32 \\
\hline 0.88 & 0 & 18.05 & 11.01 & 0 & 1.61 & 1.92 & 1.06 & 0.57 \\
\hline 2.14 & 0 & 8.70 & 6.28 & 19.80 & 1.03 & 10.61 & 0 & 17.61 \\
\hline 1,28 & 0.33 & 15.53 & 5.50 & 0 & 1.07 & 8.66 & 0 & 0 \\
\hline 0.91 & 1.92 & 30.02 & 2.51 & 0 & 1.03 & 1.02 & 0 & 1.05 \\
\hline 0.93 & 0 & 14.29 & 1.21 & 0 & 29.13 & 8.42 & 27.09 & 0.20 \\
\hline 1.06 & 0 & 10.02 & 0 & 0 & 1.07 & 7.56 & 0 & 0 \\
\hline 1.18 & 10.22 & 12.06 & 16.03 & 3.45 & 1.08 & 7.32 & 0.93 & 0 \\
\hline 1.15 & 7.56 & 11.57 & 0 & 0 & 1.53 & 2.24 & 21.65 & 1.06 \\
\hline 7.08 & 0 & 14.58 & 15.55 & 0 & 9.10 & 7.26 & 0.29 & 3.30 \\
\hline 1.02 & 0 & 20.25 & 0 & 0 & 3.72 & 1.06 & 0 & 0 \\
\hline 1.53 & 0 & 17.28 & 18.73 & 2.20 & 34.06 & 13.34 & 0 & 30.06 \\
\hline
\end{tabular}

The averaged cross section is [0.729 0.772] and for $\pm 5 \% \mathrm{LCL}=\left[\begin{array}{ll}0.693 & 0.733\end{array}\right]$ (formula (5)), and UCL $=$
[0.765 0.811] (formula (4)), the service will be ranked according to these criteria. So, for example, for SCM 4 the core is $(0.653+0.688) / 2=0.6705<0.693$ so it has the rank 
$\mathrm{C}$, for SCM 8 the core is $(0.677+0.714) / 2=0.6955>0.693$

so it has the rank B, for SCM 10 the core is $(0.778+$

$0.825) / 2=0.8015<0$. So it has the rank B, for SCM 17 the core is $(0.797+0.851) / 2=0.824>0.811$ so it has the rank A.

Table 7 Ranking services in terms of quality

\begin{tabular}{|c|c|c|c|c|c|c|}
\hline Product ID & TD & $\mathrm{C}(\mathrm{H} / \mathrm{M} / \mathrm{L})$ & DP & DT & $\mathrm{BD}$ & FAM4QS \\
\hline SCM 14 & 3T, WO, J & $\mathrm{H}$ & $\mathrm{A}$ & $\mathrm{OH}$ & FE, OL, IN & {$[0.620,0.656]$} \\
\hline SCM 4 & 3T, WO, J & $\mathrm{H}$ & $\mathrm{A}$ & IN & FE, OL, IN & {$[0.653,0.688]$} \\
\hline SCM 8 & 3T, WO, J & $\mathrm{H}$ & $\mathrm{A}$ & IN & FE, OL, IN & {$[0.677,0.714]$} \\
\hline SCM 1 & $3 \mathrm{~T}, \mathrm{WO}, \mathrm{J}$ & $\mathrm{H}$ & $\mathrm{A}$ & $\mathrm{OH}$ & FE, OL, IN & {$[0.678,0.715]$} \\
\hline SCM 2 & 3T, WO, J & $\mathrm{H}$ & $\mathrm{A}$ & $\mathrm{IN}$ & FE, OL, IN & {$[0.697,0.736]$} \\
\hline SCM 13 & $3 \mathrm{~T}, \mathrm{WO}, \mathrm{J}$ & $\mathrm{H}$ & $\mathrm{A}$ & $\mathrm{OH}$ & FE, OL, IN & {$[0.713,0.755]$} \\
\hline SCM 15 & $3 \mathrm{~T}, \mathrm{WO}, \mathrm{J}$ & $\mathrm{H}$ & $\mathrm{A}$ & IN & FE, OL, IN & {$[0.720,0.760]$} \\
\hline SCM 11 & $3 \mathrm{~T}, \mathrm{WO}, \mathrm{J}$ & $\mathrm{H}$ & $\mathrm{A}$ & $\mathrm{OH}$ & FE, OL, IN & {$[0.725,0.765]$} \\
\hline SCM 3 & 3T, WO, J & $\mathrm{H}$ & $\mathrm{A}$ & $\mathrm{OH}$ & FE, OL, IN & {$[0.726,0.765]$} \\
\hline SCM 7 & 3T, WO, J & $\mathrm{H}$ & $\mathrm{A}$ & $\mathrm{IN}$ & FE, OL, IN & {$[0.728,0.768]$} \\
\hline SCM 16 & 3T, WO, J & $\mathrm{H}$ & $\mathrm{A}$ & IN & FE, OL, IN & {$[0.737,0.781]$} \\
\hline SCM 9 & $3 \mathrm{~T}, \mathrm{WO}, \mathrm{J}$ & $\mathrm{H}$ & $\mathrm{A}$ & IN & FE, OL, IN & {$[0.745,0.793]$} \\
\hline SCM 12 & 3T, WO, J & $\mathrm{H}$ & $\mathrm{A}$ & IN & FE, OL, IN & {$[0.757,0.804]$} \\
\hline SCM 6 & $3 \mathrm{~T}, \mathrm{WO}, \mathrm{J}$ & $\mathrm{H}$ & $\mathrm{A}$ & IN & FE, OL, IN & {$[0.765,0.809]$} \\
\hline SCM 10 & 3T, WO, J & $\mathrm{H}$ & $\mathrm{A}$ & $\mathrm{OH}$ & FE, OL, IN & {$[0.778,0.825]$} \\
\hline SCM 17 & 3T, WO, J & $\mathrm{H}$ & $\mathrm{A}$ & $\mathrm{OH}$ & FE, OL, IN & {$[0.797,0.851]$} \\
\hline SCM 5 & $3 \mathrm{~T}, \mathrm{WO}, \mathrm{J}$ & $\mathrm{H}$ & $\mathrm{A}$ & IN & FE, OL, IN & {$[0.866,0.921]$} \\
\hline
\end{tabular}

Table 8 Service estimates

\begin{tabular}{|c|c|c|c|c|c|c|c|}
\hline Product ID & TD & $\mathrm{C}(\mathrm{H} / \mathrm{M} / \mathrm{L})$ & DP & DT & $\mathrm{BD}$ & FAM4QS & RANK \\
\hline SCM 14 & $3 \mathrm{~T}, \mathrm{WO}, \mathrm{J}$ & $\mathrm{H}$ & $\mathrm{A}$ & $\mathrm{OH}$ & FE, OL, IN & {$[0.620,0.656]$} & $\mathrm{C}$ \\
\hline SCM 4 & $3 \mathrm{~T}, \mathrm{WO}, \mathrm{J}$ & $\mathrm{H}$ & $\mathrm{A}$ & IN & FE, OL, IN & {$[0.653,0.688]$} & $\mathrm{C}$ \\
\hline SCM 8 & $3 \mathrm{~T}, \mathrm{WO}, \mathrm{J}$ & $\mathrm{H}$ & $\mathrm{A}$ & IN & FE, OL, IN & {$[0.677,0.714]$} & $\mathrm{B}$ \\
\hline SCM 1 & $3 \mathrm{~T}, \mathrm{WO}, \mathrm{J}$ & $\mathrm{H}$ & $\mathrm{A}$ & $\mathrm{OH}$ & FE, OL, IN & {$[0.678,0.715]$} & $\mathrm{B}$ \\
\hline SCM 2 & $3 \mathrm{~T}, \mathrm{WO}, \mathrm{J}$ & $\mathrm{H}$ & $\mathrm{A}$ & IN & FE, OL, IN & {$[0.697,0.736]$} & $\mathrm{B}$ \\
\hline SCM 13 & $3 \mathrm{~T}, \mathrm{WO}, \mathrm{J}$ & $\mathrm{H}$ & $\mathrm{A}$ & $\mathrm{OH}$ & FE, OL, IN & {$[0.713,0.755]$} & $\mathrm{B}$ \\
\hline SCM 15 & $3 \mathrm{~T}, \mathrm{WO}, \mathrm{J}$ & $\mathrm{H}$ & $\mathrm{A}$ & IN & FE, OL, IN & {$[0.720,0.760]$} & $\mathrm{B}$ \\
\hline SCM 11 & $3 \mathrm{~T}, \mathrm{WO}, \mathrm{J}$ & $\mathrm{H}$ & $\mathrm{A}$ & $\mathrm{OH}$ & FE, OL, IN & {$[0.725,0.765]$} & $\mathrm{B}$ \\
\hline SCM 3 & 3T, WO, J & $\mathrm{H}$ & $\mathrm{A}$ & $\mathrm{OH}$ & FE, OL, IN & {$[0.726,0.765]$} & $\mathrm{B}$ \\
\hline SCM 7 & $3 \mathrm{~T}, \mathrm{WO}, \mathrm{J}$ & $\mathrm{H}$ & $\mathrm{A}$ & IN & FE, OL, IN & {$[0.728,0.768]$} & B \\
\hline SCM 16 & $3 \mathrm{~T}, \mathrm{WO}, \mathrm{J}$ & $\mathrm{H}$ & $\mathrm{A}$ & IN & FE, OL, IN & {$[0.737,0.781]$} & $\mathrm{B}$ \\
\hline SCM 9 & $3 \mathrm{~T}, \mathrm{WO}, \mathrm{J}$ & $\mathrm{H}$ & $\mathrm{A}$ & IN & FE, OL, IN & {$[0.745,0.793]$} & $\mathrm{B}$ \\
\hline SCM 12 & $3 \mathrm{~T}, \mathrm{WO}, \mathrm{J}$ & $\mathrm{H}$ & $\mathrm{A}$ & IN & FE, OL, IN & {$[0.757,0.804]$} & $\mathrm{B}$ \\
\hline SCM 6 & $3 \mathrm{~T}, \mathrm{WO}, \mathrm{J}$ & $\mathrm{H}$ & $\mathrm{A}$ & IN & FE, OL, IN & {$[0.765,0.809]$} & $\mathrm{B}$ \\
\hline SCM 10 & $3 \mathrm{~T}, \mathrm{WO}, \mathrm{J}$ & $\mathrm{H}$ & $\mathrm{A}$ & $\mathrm{OH}$ & FE, OL, IN & {$[0.778,0.825]$} & $\mathrm{B}$ \\
\hline SCM 17 & $3 \mathrm{~T}, \mathrm{WO}, \mathrm{J}$ & $\mathrm{H}$ & $\mathrm{A}$ & $\mathrm{OH}$ & FE, OL, IN & {$[0.797,0.851]$} & $\mathrm{A}$ \\
\hline SCM 5 & $3 \mathrm{~T}, \mathrm{WO}, \mathrm{J}$ & $\mathrm{H}$ & A & IN & FE, OL, IN & {$[0.866,0.921]$} & $\mathrm{A}$ \\
\hline
\end{tabular}

From calculation using FAM4QS as can be seen in Fig. 5 , it can be concluded that the best result for the number of user requests and the average time of solving them according to the adopted criteria has been achieved,regarding supply, for the chain 5 (SCM 5), and the worst result for the chain 14. If the chain 14 (SCM 14) isanalyzed as the worse performance regarding the supply it can be concluded that the reasons are the following:

- Analysis and specification requirements were done badly and they are incomplete.

- Unavailability of business users for developers.

- Insufficient team confidence that develops the application - programmers, and occasional absence from the team.

- The lack of interaction between the requirement specifications and the end users (the impact of user towards the requirements specification is negligible).

- Non-dynamics of system (rate of change of the system or bad system update).

Due to increase in the success rate and reduced tendency of negative trend in SCM 14 and chains with similar characteristics the following steps are suggested:

- A detailed analysis of requirements and greater flexibility of the model or system (easy and quick adaptability of new requirement specifications towards new requests).

- Improvements in communication between business users and developers (larger number of direct meetings, more frequent communication by e-mail, Skype, telephone ...).

- Raising the quality of human relations, working environment and greater control over nonattendance.

- Establishment of direct link between end users and service providers.

- Increasing the speed and level of system update.

\section{CONCLUSION}

Within AM4SCM, a mathematical model was defined for evaluating the quality of the service provided which solves the problem of pre-existing models with imprecise estimates of parameters. Evaluations of the team of experts have been used while assessing weight coefficients and other parameters relevant to the system. (Progression) arithmetic mean - mean estimates of experts is usually taken for the assessment of weight element in six-step method for improving the quality of service which was upgraded. 
If the phenomenon of observed evaluation has a normal distribution, then it is good to take the mean of such assessment parameter, but if not then it is often better to take different assessment. Distribution of the assessment of the team of experts was regarded as fuzzy number and for easy calculation unsymmetrical triangular fuzzy number. Thus, it has provided the opportunity to get fuzzy number instead of a number of such estimates of the entire system, i.e. interval of values with different values of the membership function. Defuzzification provided better value than the standard procedure. To avoid stiff conclusion, i.e. the answer for the system quality assessment is a number, the response interval value is taken which is actually alpha-section stage as the number of output where alpha desired grade of membership is taken.

Fuzzy aggregation environments used for assessing the quality of supply chains are degree environments where we have taken different values for degrees which were conditioned by different nature of parameters. Due to these differences, it follows that there are more or less disjunctive or conjunctive forms of selected aggregation functions. By applying our method on 17 selected homogeneous supply chains, the analysis of the best and the worst chain provided the conclusion that it is necessary to analyze the requirements and increase the flexibility of the model, improve communication between business users and developers, raise the quality of interpersonal relationships, exercise control of absenteeism, establish direct connection between end users with service providers and increase the speed and level of system update.

Working with large systems facilitates and accelerates process of finding new methods such as working with neural networks in combination with FAM4QS.

Likewise the traditional method, this method can also use software packages so the user can automatically receive, on the basis of given criteria, assessment of the quality of service in order to facilitate further decisionmaking. The software that we developed is written in $\mathrm{C} \#$ and allows commercial use of FAM4QS. It will be further developed, i.e. for large systems, where FAM4QS will be combined with neural networks.

\section{Acknowledgements}

The research for this article was conducted under the project "Development of software to manage repair and installation of brake systems for rail vehicles", Ministry of Science of Serbia, no. 035050, for the period 2011-2017.

\section{REFERENCES}

[1] Petrovic, D., Xie, Y., Burnham, K., \& Petrovic, R. (2008). Coordinated control of distribution supply chains in the presence of fuzzy customer demand. European Journal of Operational Research, 185(1), 146-158. https://doi.org/10.1016/j.ejor.2006.12.020

[2] Monczka, M. R., Handfield, B. R., Giunipero, C. L., \& Patterson, L. J. (2015). Purchasing and supply chain management, Cengage Learning.

[3] Mert, B. \& Ayse, D. (2013). Using rough set theory for supply chain management process in business. XI Balkan conference on operational research (BALCOR 2013), Belgrade-Zlatibor, Serbia, 367-374.
[4] Lysons, K. \& Farrington, B. (2006). Purchasing and supply chain management, Pearson Education.

[5] Christopher, M. (2016). Logistics \& supply chain management, Pearson Higher Ed.

[6] Cheng, Z., Xiao, J., Xie, K., \& Huang, X. (2013). Optimal product quality of supply chain based on information traceability in fashion and textiles industry: an adverse logistics perspective. Mathematical Problems in Engineering, Vol. 2013, Article ID 629363, 13 pages. https://doi.org/10.1155/2013/629363

[7] Ross, D. F. (2004). Distribution: Planning and Control Managing in the Era of Supply Chain Management, Second Edition, Springer US.

[8] Buchmeister, B., Friscic. D., \& Palcic, I. (2013). Impact of demand changes and supply chain's level constraints on bullwhip effect. Advances in Production Engineering \& Management, 8(4), 199-208. https://doi.org/10.14743/apem2013.4.167

[9] Lin, C., Hung, H., Wu, J., \& Lin, B. (2002). A Knowledge Management Architecture in Collaborative Supply Chain. Journal of Computer Information Systems, 42(5), 83-94.

[10] Ganguly, A., Nilchiani, R., \& Farr, J. V. (2009). Evaluating agility in corporate enterprises. International Journal of Production Economics, 118(2), 410-423. https://doi.org/10.1016/j.ijpe.2008.12.009

[11] Overby, E., Bharadwaj, A., \& Sambamurthy, V. (2006). Enterprise agility and the enabling role of information technology. European Journal of Information Systems, 15(2), 120-131. https://doi.org/10.1057/palgrave.ejis.3000600

[12] Sambamurthy, V., Bharadwaj, A., \& Grover, V. (2003). Shaping agility through digital options: Reconceptualizing the role of information technology in contemporary firms. MIS Quarterly, 27(2), 237-263. https://doi.org/10.2307/30036530

[13] Christopher, M. (1998). Logistics and Supply Chain Management, Prentice Hall, London.

[14] Van Hoek, R. I., Harrison, A., \& Christopher, M. (2001). Measuring agile capabilities in the supply chain. International Journal of Operations \& Production Management, 21(1/2), 126-147. https://doi.org/10.1108/01443570110358495

[15] Leuschner, R., Dale S. R., \& Charvet, F. F. (2013). A metaanalysis of supply chain integration and firm performance. Journal of Supply Chain Management, 49(2), 34-57. https://doi.org/10.1111/jscm.12013

[16] Adams, F. G., Richey, R. G., Autry, C. W., Morgan, T. R., \& Gabler, C. B. (2014). Supply chain collaboration, integration, and relational technology: how complex operant resources increase performance outcomes. Journal of Business Logistics, 35(4), 299-317. https://doi.org/10.1111/jbl.12074

[17] Huo, B., Huo, B., Han, Z., Han, Z., Prajogo, D., \& Prajogo, D. (2016). Antecedents and consequences of supply chain information integration: a resource-based view. Supply Chain Management: An International Journal, 21(6), 661677. https://doi.org/10.1108/SCM-08-2015-0336

[18] Huo, B., Qi, Y., Wang, Z., \& Zhao, X. (2014). The impact of supply chain integration on firm performance: The moderating role of competitive strategy. Supply Chain Management: An International Journal, 19(4), 369-384. https://doi.org/10.1108/SCM-03-2013-0096

[19] Kim, S. W. (2006). Effects of supply chain management practices, integration and competition capability on performance. Supply Chain Management: An International Journal, 11(3), 241-248. https://doi.org/10.1108/13598540610662149

[20] Zhao, L., Huo, B., Sun, L., \& Zhao, X. 2013). The impact of supply chain risk on supply chain integration and company performance: a global investigation. Supply Chain Management: An International Journal, 18(2), 115-131. 
https://doi.org/10.1108/13598541311318773

[21] Nagurney, A., Saberi, S., Shukla, S., \& Floden, J. (2015) Supply chain network competition in price and quality with multiple manufacturers and freight service providers. Transportation Research Part E: Logistics and Transportation Review, 77, 248-267. https://doi.org/10.1016/j.tre.2015.03.001

[22] Jia, R. \& Reich, B. H. (2013). IT service climate, antecedents and IT service quality outcomes: Some initial evidence. Journal of Strategic Information Systems, 22(1), 51-69. https://doi.org/10.1016/j.jsis.2012.10.001

[23] Zhou, H., Shou, Y., Zhai, X., Li, L., Wood, C., \& Wu, X. (2014). Supply chain practice and information quality: A supply chain strategy study. International Journal of Production Economics, 147, 624-633. https://doi.org/10.1016/j.ijpe.2013.08.025

[24] Ge, M., \& Helfert, M. (2013). Impact of information quality on supply chain decisions. Journal of Computer Information Systems, 53(4), 59-67. https://doi.org/10.1080/08874417.2013.11645651

[25] Khurana, M., Mishra, P., \& Singh, A. (2011). Barriers to information sharing in supply chain of manufacturing industries. International Journal of Manufacturing Systems, 1, 9-29. https://doi.org/10.3923/ijmsaj.2011.9.29

[26] Yang, T.-M. \& Maxwell, T. A. (2011). Information-sharing in public organizations: A literature review of interpersonal, intra-organizational and interorganizational success factors. Government Information Quarterly, 28, 164-175. https://doi.org/10.1016/i.giq.2010.06.008

[27] Lotfi, Z., Mukhtar, M., Sahran, S., \& Zadeh, A. T. (2013). Information Sharing in Supply Chain Management. $4^{\text {th }}$ International Conference on Electrical Engineering and Informatics, Procedia Technology, 11, 298-304. https://doi.org/10.1016/j.protcy.2013.12.194

[28] Marinagi, C., Trivellas, P., \& Reklitis, P. (2015). Information quality and supply chain performance: The mediating role of information sharing. Procedia-Social and Behavioral Sciences, 175, 473-479. https://doi.org/10.1016/j.sbspro.2015.01.1225

[29] Wong, C. W., Lai, K. H., Cheng, T. C. E., \& Lun, Y. V. (2015). The role of IT-enabled collaborative decision making in inter-organizational information integration to improve customer service performance. International Journal of Production Economics, 159, 56-65. https://doi.org/10.1016/j.ijpe.2014.02.019

[30] Klement, E. P. \& Mesiar, R. (2005). Logical, algebraic, analytic, and probabilistic aspects of triangular norms, $1^{\text {st }}$ edition, Elsevier, Amsterdam.

[31] Klement, E. P., Mesiar, R., \& Pap, E. (2000). Triangular Norms, Springer. https://doi.org/10.1007/978-94-015-9540-7

[32] Marković, V. \& Maksimović, R. (2012). A Contribution to Continual Software Service Improvement Based on the Sixstep Service Improvement Method. International Journal of Software Engineering and Knowledge Engineering, 22(4), 121. https://doi.org/10.1142/S0218194012500143

[33] Klir, G. J. \& Yuan, B. (1995). Fuzzy Sets and Fuzzy Logic: Theory and Applications, Prentice Hall, New Jersey.

[34] Dujmović, J. J. \& Bai, H. (2006). Evaluation and Comparison of Search Engines Using the LSP Method. ComSIS, 3(2), 31-56. https://doi.org/10.2298/CSIS0602031D

[35] Ott, E. R., Schilling, E. G., Neubauer, D. V. (2005). Process QualityControl: Troubleshooting and Interpretation of Data, $4^{\text {th }}$ Edition, ASQ.

[36] Dujmović, J. J. \& Nagashima, H. (2006). LSP method and its use for evaluation of Java IDEs. Int. J. Approx. Reason, 41(1), 3-22. https://doi.org/10.1016/j.ijar.2005.06.006

\section{Contact information:}

Milovan TOMAŠEVIĆ, Research Associate, PhD student University of Novi Sad, Faculty of Technical Sciences Trg Dositeja Obradovica 6, 21 000, Novi Sad, Serbia mt@uns.ac.rs

Nebojša RALEVIĆ, PhD, Full Professor University of Novi Sad, Faculty of Technical Sciences Trg Dositeja Obradovica 6, 21 000, Novi Sad, Serbia nralevic@uns.ac.rs

Željko STEVIĆ, Assistant, PhD student University of East Sarajevo,

Faculty of Transport and Traffic Engineering Doboj Misica 52, 74 000, Doboj, Bosnia and Herzegovina zeljkostevic88@yahoo.com

Vidan MARKOVIĆ, PhD, Associate Professor University of Novi Sad, Faculty of Technical Sciences Trg Dositeja Obradovica 6, 21 000, Novi Sad, Serbia vmarkovic@uns.ac.rs

\section{Zdravko TEŠIĆ, PhD, Full Professor}

University of Novi Sad, Faculty of Technical Sciences Trg Dositeja Obradovica 6, 21 000, Novi Sad, Serbia ztesic@uns.ac.rs 